\section{Kidney \\ Blood Pressure Research}

\title{
Rosiglitazone Did Not Induce Acute Kidney Injury in Normocholesterolemic Rats Despite Reduction in Glomerular Filtration Rate
}

\author{
Cristiano Dias Rildo A. Volpini Claudia M.B. Helou
}

Laboratório de Pesquisa Básica (LIM-12), Nefrologia, Hospital das Clínicas da Faculdade de Medicina da Universidade de São Paulo, São Paulo/SP, Brazil

\section{Key Words}

Acute kidney injury • Hypercholesterolemia • Rosiglitazone • Angiotensin II • uNGAL

\begin{abstract}
Background/Aims: Rosiglitazone (RGL) has been used to ameliorate lipids homeostasis and also to treat inflammatory diseases. However, RGL may reduce renal blood flow and glomerular filtration rate (GFR) predisposing to acute kidney injury (AKI). We investigated whether the treatment with RGL induces AKI in normocholesterolemic (NC) and hypercholesterolemic (HC) rats. Methods: We measured GFR by inulin clearance technique and we quantified urinary neutrophil gelatinase-associated lipocalin (UNGAL) in all groups at baseline and during Ang II-stimulated vasoconstriction. Moreover, we evaluated the presence of renal damaged by histologic examination. Results: At baseline, NC and HC had normal and similar GFR. RGL treatment reduced GFR only in NC+RGL. Unexpectedly, $H C+R G L$ showed high levels of $U N G A L$ although GFR was at normal range. During Ang II-stimulated vasoconstriction, all groups showed reduction in GFR to the same range and we found high levels of UNGAL and high score of renal damage in $\mathrm{HC}$ and $\mathrm{HC}+\mathrm{RGL}$. Conclusion: RGL acts distinctly in normocholesterolemia and in hypercholesterolemia. Reduction in GFR provoked by RGL treatment did not allow the diagnosis of AKI in NC even in the presence of ANG II-stimulated vasoconstriction. However, AKI was diagnosed in $\mathrm{HC}+\mathrm{RGL}$ at baseline although GFR was within normal range.
\end{abstract}

Copyright $\odot 2014$ S. Karger AG, Basel

\section{Introduction}

Rosiglitazone (RGL) is an insulin-sensitizing drug that acts as a ligand for the gamma peroxisome proliferator-activated receptor (PPAR $\gamma$ ) ameliorating glucose and lipids homeostasis [1]. Therefore, RGL also has anti-inflammatory properties by inhibiting nuclear transcription of cytokines, chemokines and adhesion molecules [1, 2]. For this reason, RGL has also been used as a novel therapy for inflammatory diseases [2, 3]. 


\section{Kidney \\ Blood Pressure Research}

\begin{tabular}{l|l}
\hline DOI: $10.1159 / 000355767$ & C 2014 S. Karger AG, Basel \\
\hline
\end{tabular}

Published online: April 08, 2014

www.karger.com/kbr

In recent studies, Liu et al $[4,5]$ showed inhibition of pro-apoptotic molecules production and myeloperoxidase expression in ischemic/reperfused hearts of hypercholesterolemic rabbits treated with RGL. They suggested that RGL may be a therapeutic choice to treat hypercholesterolemic patients with ischemic heart disease. However, side effects of edema and congestive heart failure have been reported in diabetic patients treated with RGL [6, 7]. Moreover, an updated meta-analysis showed increased risk for myorcardial infarction in patients treated with RGL [8]. Thus, the European Medicines Agency suspended RGL from the European market since September 2010. Despite well documented side effects, many other studies continue to indicate the use of RGL in diabetic and nondiabetic patients due to its anti-inflammatory property $[9,10]$.

Studies performed with normal rodents showed increment in sodium tubular reabsorption that was associated or not with a reduction in glomerular filtration rate (GFR) $[11,12]$. In addition, the treatment with RGL provoked a direct vascular effect that decreased blood pressure and vasodilated both pre- and postglomerular arterioles [12, 13]. In these situations, a reduction in GFR may occur associated with a fall in blood supply to renal epithelial tubular cells that may predispose to the development of acute kidney injury (AKI). The risk of ischemic AKI increases if angiotensin II (Ang II) that exerts a vasoconstriction state is present. This possibility is not rare in critically ill patients in whom hemodynamic instability is present and Ang II plays an important role to restore blood pressure.

The aim of this study was to verify if reduced GFR by RGL treatment associated or not with a potent vasoconstrictor such as Ang II may induce renal injury in normocholesterolemic rats. Moreover, we have also tested if RGL may act distinctly in the presence of hypercholesterolemia because this drug has been indicated to ameliorate lipids homeostasis.

\section{Materials and Methods}

The study was approved by the Research Ethics Committee of our institution (Comissão de Ética para Análise de Projetos de Pesquisa - CAPPesq, da Diretoria Clínica do Hospital das Clínicas da Faculdade de Medicina da Universidade de São Paulo) and conducted according to the National Research Council Guide for the Care and Use of Laboratory Animals [14].

Male Wistar rats, weighing $\sim 200 \mathrm{~g}$, obtained from the Animal Center of the Faculdade de Medicina da Universidade de São Paulo were randomly housed in individual cages with free access to food and water for eight days. We fed the animals with a standard diet (normocholesterolemic rats - NC) or a standard diet supplemented with $4 \%(\mathrm{w} / \mathrm{w})$ cholesterol and $1 \%(\mathrm{w} / \mathrm{w})$ cholic acid (hypercholesterolemic rats - HC) [15, 16]. Both NC and HC were treated or not with rosiglitazone maleate (Avandia, GlaxoSmithKline, GSK) at a level of $48 \mathrm{mg} / \mathrm{kg}$ diet for eight days. For all surgical procedures, we anesthetized the animals with sodium thionembutal ( $50 \mathrm{mg} / \mathrm{kg}$ b.w., i.p.).

The groups studied were: I) NC ( $n=11)$, consisting of normocholesterolemic rats; II) NC + RGL ( $n=10)$, consisting of normocholesterolemic rats treated with RGL; III) HC ( $n=12)$, consisting of hypercholesterolemic rats; IV) HC+RGL ( $\mathrm{n}=8)$, consisting of hypercholesterolemic rats treated with RGL.

\section{Clearance Studies}

All animals were submitted to the same protocol to evaluate GFR, diuresis, urinary sodium and potassium excretion by measuring inulin clearance as we have previously described [15]. Briefly, we placed catheters in trachea, jugular veins, carotid artery and bladder. Thereafter, we intravenously administered a priming dose of inulin $(100 \mathrm{mg} / \mathrm{kg}$ b.w.) that was followed by a constant inulin infusion $(10 \mathrm{mg} / \mathrm{kg}$ b.w. diluted in $0.9 \%$ saline) at a rate of $0.04 \mathrm{ml} / \mathrm{min}$. After a 30-min recovery period, we collected two urine samples at 30-min intervals as baseline period. Then, we started Ang II intravenous infusion $(40 \mathrm{ng} / \mathrm{kg}$ b.w.) at a rate of $0.04 \mathrm{ml} / \mathrm{min}$ [17] and we waited for a 15-min stabilization period. After that, we collected two further urine samples at 20-min intervals. We also collected blood samples at the beginning and at the end of experiments. In all urine and blood samples, we assayed inulin by the anthrone method [18] and we quantified $\mathrm{Na}^{+}$by flame photometry (CELM-FC280). In addition, we also measured glucose, triglycerides, 


\section{Kidney \\ Blood Pressure Research}

Fig. 1. Study design to collect urine for UNGAL measurements at baseline and during angiotensin II infusion. The animals were anesthetized and submitted to the same protocol of clearance studies to collect urine samples for 30 minutes. Thus, all animals received a constant $0.9 \%$ saline infusion at a rate of $0.04 \mathrm{ml} / \mathrm{min}$ during all procedures. a, after waiting a 30-minute surgery recovery period, we collected a urine sample after waiting a baseline period of 30-min. b, after waiting a 30-minute surgery recovery period, we collected a urine sample after waiting for 105 minutes, corresponding the same period of Ang II infusion in clearance studies. Ang II, angiotensin II; uNGAL, urinary neuthrophil gelatinase-associated lipocalin.
Kidney Blood Press Res 2013;38:186-195

\begin{tabular}{l|l}
\hline DOI: $10.1159 / 000355767$ & (c 2014 S. Karger AG, Basel
\end{tabular}

Published online: April 08, 2014

www.karger.com/kbr

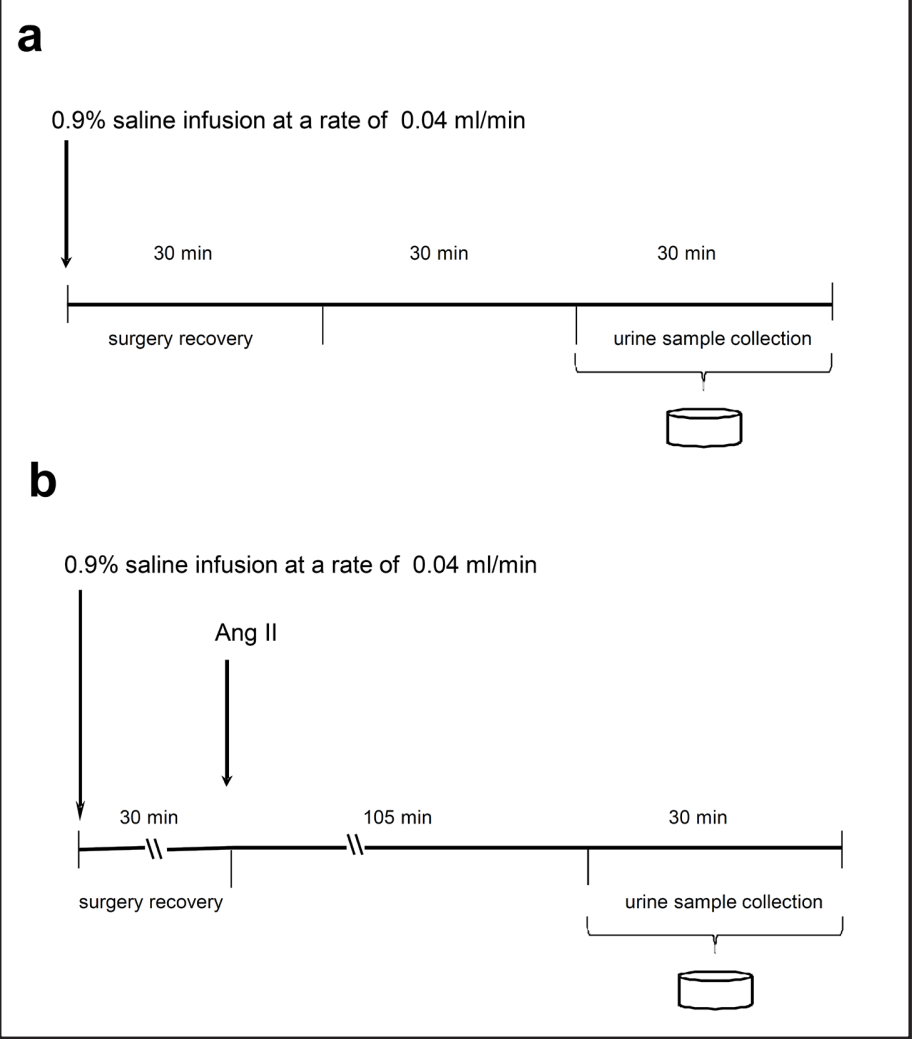

total and high-density (HDL) cholesterol in the plasma by colorimetric method (Labtest ${ }^{\text {, }}$, Lagoa Santa, Brazil). In all experiments, we also placed a polyethylene (PE-60) catheter in the carotid artery to measure the mean arterial pressure (AP). We performed three consecutive AP determinations at the beginning of each period of clearance studies. The mean values of AP determinations were averaged to obtain a single value of baseline and Ang II periods and they were expressed in $\mathrm{mm} \mathrm{Hg}$.

\section{uNGAL Measurements}

We quantified uNGAL by ELISA technique (Rat NGAL ELISA Kit, BioPorto, Gentofte, Denmark) in other two sets of experiments. We collected the urine samples from anesthetized animals at baseline and during Ang II infusion, as illustrated in fig. 1.

\section{Histologic Examination}

For histologic examination, the excised left kidneys were fixed in Bouin's solution. The kidney tissue block was dehydrated in graded alcohol, embedded in paraffin, cut at $4 \mu \mathrm{m}$, and then stained with periodic acid-Schiff reagent for renal lesions examination. Thirty grid fields measuring $0.245 \mathrm{~mm}^{2}$ each were randomly selected at 400x magnification and scored for each rat. Each grid field was assigned one of five categories according to the following criteria: 0 , less than $5 \%$ of grid field area presenting tubular epithelial cell swelling, vacuolar degeneration, necrosis, and involving desquamation; $1,5-25 \%$ of grid field area; 2 , $25-50 \%$ of grid field area; 3 , similar changes involving $50-75 \%$ of grid field area; 4 , more than $75 \%$ of grid field area of renal lesions. To minimize observer bias, the morphometric examination was performed in a blinded manner without knowledge of the treatment group from which the tissue originated. The mean score for each rat and the mean score for each group were calculated [19].

Thiobarbituric Acid Reactive Substances (TBARS) and Serum Magnesium Assays

We determined the levels of TBARS in all samples of the serum collected at the end of Ang II infusion in clearance studies using the method described by Shimizu MHM et al [20]. Furthermore, we submitted another set of animals to the same protocol, which is illustrated in fig. $1 \mathrm{~A}$, to collect the serum 


\section{Kidney Blood Pressure Research}

Table 1. Characteristics of normal and hypercholesterolemic rats treated with or without rosiglitazone

\begin{tabular}{lcccc}
\hline & \multicolumn{2}{c}{ Normal rats } & \multicolumn{2}{c}{ Hypercholesterolemic rats } \\
\cline { 2 - 5 } & $\mathrm{NC}$ & $\mathrm{RGL}$ & $\mathrm{HC}$ & $\mathrm{RGL}$ \\
\hline Number of rats & 12 & 10 & 13 & 9 \\
Initial body weight, g & $204 \pm 6$ & $202 \pm 8$ & $202 \pm 4$ & $210 \pm 5$ \\
Final body weight, g & $252 \pm 6$ & $251 \pm 7$ & $225 \pm 3$ & $222 \pm 11$ \\
Average food intake, g/day & $24.4 \pm 1.7$ & $21.5 \pm 1.8$ & $23.9 \pm 1.5$ & $23.7 \pm 1.0$ \\
Total cholesterol, mmol/l & $2.36 \pm 0.12$ & $1.96 \pm 0.23$ & $6.28 \pm 0.24^{*}$ & $4.83 \pm 0.53^{* \# \#}$ \\
Non-HDL-cholesterol, mmol/l & $1.25 \pm 0.13$ & $0.98 \pm 0.27$ & $5.38 \pm 0.49^{*}$ & $4.62 \pm 0.57^{*}$ \\
HDL-cholesterol, mmol/l & $0.60 \pm 0.03$ & $0.55 \pm 0.05$ & $0.14 \pm 0.02^{*}$ & $0.13 \pm 0.03^{*}$ \\
Triglycerides, mmol/l & $1.49 \pm 0.23$ & $1.27 \pm 0.15$ & $1.14 \pm 0.10$ & $0.69 \pm 0.09 \S$ \\
Glucose, mmol/l & $5.70 \pm 0.29$ & $5.68 \pm 0.28$ & $6.34 \pm 0.17$ & $5.36 \pm 0.26^{\#}$ \\
Plasma $\mathrm{Na}^{+}, \mathrm{mmol} / \mathrm{l}$ & $139 \pm 1$ & $139 \pm 2$ & $141 \pm 1$ & $142 \pm 2$ \\
Plasma $\mathrm{K}^{+}, \mathrm{mmol} / \mathrm{l}$ & $4.0 \pm 0.1$ & $4.1 \pm 0.1$ & $3.9 \pm 0.1$ & $3.6 \pm 0.1$ \\
\hline Data & $4.05 \mathrm{pr}$ &
\end{tabular}

Data are expressed as mean \pm SEM. $* \mathrm{p}<0.001$ vs. NC and NC+RGL; ${ }^{*} \mathrm{p}<0.05$ vs. HC and ${ }^{\# \#} \mathrm{p}<0.01$ vs. $\mathrm{HC} ; \S \mathrm{p}<0.05$ vs. NC

in basal conditions to determine the levels of TBARS and concentrations of magnesium. We assayed the concentrations of magnesium by colorimetric method (Labtest ${ }^{\circledR}$, Lagoa Santa, Brazil).

\section{Statistical Analysis}

Data were expressed as mean \pm standard error of the mean (SEM). We used paired Student's $t$-tests for dual comparisons on the same rat and we used unpaired $t$-tests for comparisons between groups. The analysis of variance (ANOVA) and the Student-Newman-Keuls post hoc test were used for comparisons among groups. Values of $\mathrm{P}<0.05$ were considered significant.

\section{Results}

Table 1 summarizes the characteristics of NC and HC rats treated with or without RGL. As expected, the total cholesterol and the non-HDL-cholesterol fraction were significantly higher in HC than NC and the HDL-cholesterol fraction was significantly lower in HC than NC. The treatment with RGL did not change the biochemical profile in NC, but it modified in $\mathrm{HC}$. The total cholesterol and glucose levels were significantly lower in the serum of HC+RGL than HC. In addition, the levels of triglycerides, non-HDL-cholesterol and HDL-cholesterol fractions were significantly lower in HC+RGL than in NC and NC+RGL.

\section{Renal Function at Baseline and During Acute Ang II Exposure}

As illustrated in fig. 2A, NC and HC had similar GFR and RGL treatment reduced GFR in normal rats $(\mathrm{NC}=0.79 \pm 0.03$ vs. $\mathrm{NC}+\mathrm{RGL}=0.50 \pm 0.05 \mathrm{ml} / \mathrm{min} / 100 \mathrm{~g}$ b.w., $\mathrm{p}<0.05)$ at baseline. However, the same treatment with RGL did not induce any change in GFR of hypercholesterolemic rats $(\mathrm{HC}=0.77 \pm 0.03 \mathrm{vs} . \mathrm{HC}+\mathrm{RGL}=0.84 \pm 0.04 \mathrm{ml} / \mathrm{min} / 100 \mathrm{~g}$ b.w. $)$. With regard to other parameters, AP was at normal range (fig. 2B) and urine flow, urinary sodium and potassium excretion were similar in all groups (table 2).

Nevertheless, the exposure to Ang II diminished significantly GFR in NC, $\mathrm{HC}$ and $\mathrm{HC}+\mathrm{RGL}$, and it remained at the same reduced level in NC+RGL $(\mathrm{NC}=0.61 \pm 0.05 ; \mathrm{NC}+\mathrm{RGL}=0.54 \pm$ $0.07 ; \mathrm{HC}=0.61 \pm 0.03 ; \mathrm{HC}+\mathrm{RGL}=0.64 \pm 0.06 \mathrm{ml} / \mathrm{min} / 100$ g b.w.; fig. $2 \mathrm{~A})$. Furthermore, $\mathrm{AP}$ rose from $126.0 \pm 4.1$ to $134 \pm 3.4 \mathrm{~mm} \mathrm{Hg}$ in $\mathrm{NC}, \mathrm{p}<0.05$, and it remained at the same level in the other groups (fig. 2B). Moreover, the exposure to Ang II increased urine flow, urinary sodium and potassium excretion in all groups (table 2).

\section{uNGAL Concentrations}

At baseline, NC and HC showed similar levels of uNGAL (fig. 3A). The treatment with RGL did not change the magnitude of uNGAL in normal rats $(\mathrm{NC}=10.7 \pm 1.9 \mathrm{vs}$. NC $+\mathrm{RGL}=$ $8.4 \pm 1.4 \mu \mathrm{g}$ NGAL/ mg creatinine). In contrast, HC rats treated with RGL showed high levels of uNGAL ( $\mathrm{HC}=13.0 \pm 2.3 v s$. $\mathrm{HC}+\mathrm{RGL}=38.1 \pm 11.8 \mu \mathrm{g}$ NGAL/ mg creatinine, $\mathrm{p}<0.05)$.

In the presence of Ang II, the values for uNGAL remained at the same range in NC treated 


\section{Kidney \\ Blood Pressure Research}

Kidney Blood Press Res 2013;38:186-195

DOI: 10.1159/000355767 2014

C 2014 S. Karger AG, Basel

www.karger.com/kbr

Dias/Volpini/Helou: Rosiglitazone and AKI
Fig. 2. The effects of rosiglitazone treatment on GFR and arterial pressure in normal and hypercholesterolemic rats. a, GFR was similar in NC and $\mathrm{HC}$ at baseline and the treatment with RGL had effects only in normal rats whose GFR was significantly reduced. However, the exposure to Ang II diminished GFR to the same range of NC + RGL whose levels remained low. $\mathbf{b}, \mathrm{AP}$ values were similar in all groups at baseline and the exposure to Ang II increased AP levels only in NC. Data are expressed as mean \pm SEM. ${ }^{*} \mathrm{p}<0.05$ vs. baseline evaluated by paired Student's $\mathrm{t}$ test; ${ }^{\# \#} \mathrm{p}<0.001$ vs. NC, HC and HC + RGL at baseline; ${ }^{*} \mathrm{p}<0.01$ vs. NC, HC and HC + RGL at baseline evaluated by analysis of variance followed by the Student-Newman-Keuls test. NC, normocholesterolemic rats; $\mathrm{NC}+$ RGL, normocholesterolemic rats treated with RGL; HC, hypercholesterolemic rats; $\mathrm{HC}+\mathrm{RGL}$, hypercholesterolemic rats treated with RGL; GFR, glomerular filtration rate; AP, arterial pressure; Ang II, angiotensin II; RGL, rosiglitazone.

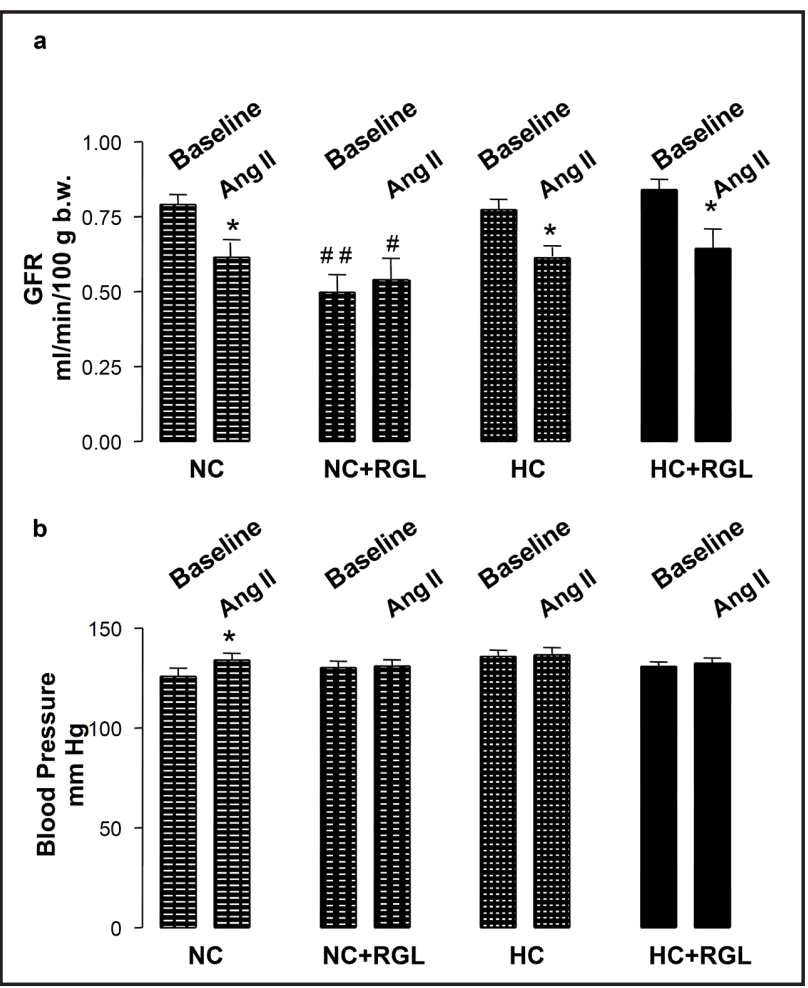

Table 2. Physiological parameters of normal and hypercholesterolemic rats treated with or without rosiglitazone at baseline and during angiotensin II infusion

\begin{tabular}{|c|c|c|c|c|c|c|c|c|}
\hline & \multicolumn{2}{|c|}{$\mathrm{NC}(\mathrm{n}=11)$} & \multicolumn{2}{|c|}{ NC + RGL $(n=10)$} & \multicolumn{2}{|c|}{$\mathrm{HC}(\mathrm{n}=12)$} & \multicolumn{2}{|c|}{$\mathrm{HC}+\mathrm{RGL}(\mathrm{n}=8)$} \\
\hline & Baseline & Ang II & Baseline & Ang II & Baseline & Ang II & Baseline & Ang II \\
\hline $\mathrm{V}, \mu \mathrm{l} / \mathrm{min}$ & $7.3 \pm 0.7$ & $11.4 \pm 1.1^{*}$ & $9.9 \pm 1.4$ & $40.4 \pm 8.1^{* *}$ & $11.0 \pm 1.6$ & $16.6 \pm 3.2^{*}$ & $6.6 \pm 0.5$ & $14.1 \pm 2.0^{* *}$ \\
\hline $\mathrm{U}_{\mathrm{Na}} \mathrm{V}, \mu \mathrm{mol} / \mathrm{min}$ & $1.01 \pm 0.24$ & $3.05 \pm 0.92^{*}$ & $1.66 \pm 0.37$ & $5.86 \pm 1.04^{* *}$ & $1.41 \pm 0.27$ & $2.62 \pm 0.47^{* *}$ & $0.78 \pm 0.14$ & $2.44 \pm 0.37^{* *}$ \\
\hline $\mathrm{U}_{\mathrm{K}} \mathrm{V}, \mu \mathrm{mol} / \mathrm{min}$ & $0.88 \pm 0.13$ & $1.21 \pm 0.14^{*}$ & $1.06 \pm 0.14$ & $2.10 \pm 0.27^{* *}$ & $0.86 \pm 0.10$ & $1.15 \pm 0.12^{*}$ & $0.64 \pm 0.13$ & $1.12 \pm 0.14^{* *}$ \\
\hline
\end{tabular}

with or without RGL (fig. 3B). On the other hand, the values for uNGAL increased significantly from $13.0 \pm 2.3$ to $20.5 \pm 6.1 \mu \mathrm{g} \mathrm{NGAL} / \mathrm{mg}$ creatinine in $\mathrm{HC}, \mathrm{p}<0.05$. In addition, uNGAL levels remained high in $\mathrm{HC}+\mathrm{RGL}$ (fig. $3 \mathrm{~B}$ ).

\section{Evaluation of Renal Damage by a Histologic Examination}

As shown in table 3, the histologic examination showed higher score of renal damage in $\mathrm{HC}$ rats treated with or without RGL than NC and NC + RGL after Ang II exposure.

\section{Evaluation of Oxidative Stress by TBARS Measurements}

At baseline, $\mathrm{NC}$ and $\mathrm{HC}$ showed similar levels of TBARS in the serum $(\mathrm{NC}=3.5 \pm 0.3$ and $\mathrm{HC}=4.1 \pm 0.3 \mathrm{nmol} / \mathrm{ml}$ ) and the treatment with RGL did not modify them (NC $+\mathrm{RGL}=3.3 \pm$ 0.4 and $\mathrm{HC}+\mathrm{RGL}=3.7 \pm 0.2 \mathrm{nmol} / \mathrm{ml}$ ). In the presence of Ang II, the levels of TBARS in the serum remained at the same range in all groups $(\mathrm{NC}=4.3 \pm 0.5 ; \mathrm{NC}+\mathrm{RGL}=4.1 \pm 0.3 ; \mathrm{HC}=$ $4.8 \pm 0.4 ; \mathrm{HC}+\mathrm{RGL}=4.0 \pm 0.3 \mathrm{nmol} / \mathrm{ml}$ ).

\section{Magnesium Concentration}

As illustrated in fig. 4, magnesium concentration was at normal range in the serum of normal rats treated with or without RGL $(\mathrm{NC}=0.85 \pm 0.03$ and $\mathrm{NC}+\mathrm{RGL}=0.74 \pm 0.05$ $\mathrm{mmol} / \mathrm{l})$. In contrast, hypomagnesemia was found in hypercholesterolemic rats treated with or without $\mathrm{RGL}(\mathrm{HC}=0.57 \pm 0.02$ and $\mathrm{HC}+\mathrm{RGL}=0.64 \pm 0.06 \mathrm{mmol} / \mathrm{l})$. 


\section{Kidney \\ Blood Pressure Research}

Kidney Blood Press Res 2013;38:186-195

DOI: 10.1159/000355767

Published onlıne: April 08, 2014

C 2014 S. Karger AG, Basel

www.karger.com/kbr

Dias/Volpini/Helou: Rosiglitazone and AKI
Fig. 3. Urinary NGAL determinations in normal and hypercholesterolemic rats treated with or without rosiglitazone. a, NGAL was quantified in urine samples of NC $(n=5)$, NC $+\operatorname{RGL}(n=4), \mathrm{HC}(\mathrm{n}=6)$ and HC + RGL $(n=5)$ at baseline. NC treated with or without RGL and HC had similar levels of urinary NGAL, but HC + RGL had significantly high levels of urinary NGAL at this time. b, in another set of animals, NGAL was quantified in urine samples of NC ( $n=8), N C+$ RGL ( $n=8), H C(n=6)$ and $\mathrm{HC}+\mathrm{RGL}(\mathrm{n}=7)$ during Ang II infusion. NC treated with or without RGL showed again similar levels of urinary NGAL, but HC and HC + RGL showed significantly high levels of urinary NGAL when they were exposed to Ang II. Data are expressed as mean \pm SEM. ${ }^{* *} \mathrm{p}<0.01$ vs. NC and NC + RGL; ${ }^{*} \mathrm{p}<0.05$ vs. NC and NC $+\mathrm{RGL} ;{ }^{*} \mathrm{p}<0.01$ vs. HC evaluated by analysis of variance followed by the Student-Newman-Keuls test. NC, normocholesterolemic rats; NC + RGL, normocholesterolemic rats treated with RGL; HC, hypercholesterolemic rats; $\mathrm{HC}+\mathrm{RGL}$, hypercholesterolemic rats treated with RGL; Ang II, angiotensin II; RGL, rosiglitazone, NGAL, neuthrophil gelatinase-associated lipocalin.

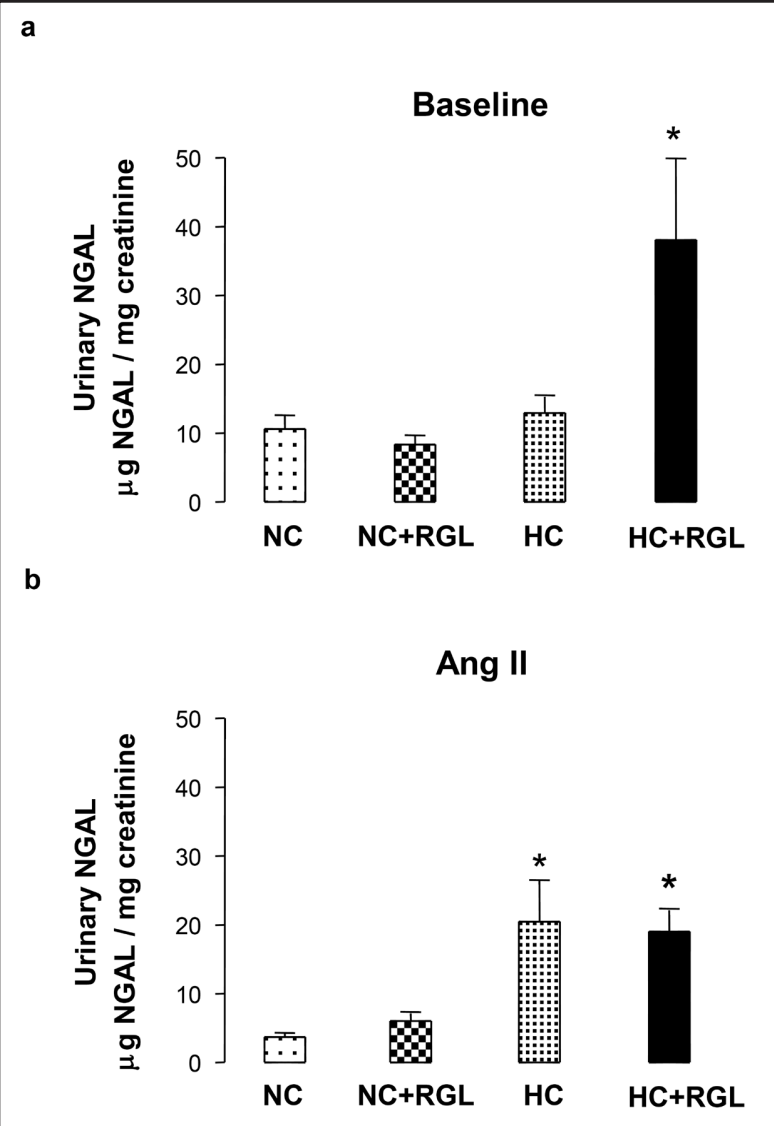

a

Ang II

Table 3. Score of renal damage in normal and hypercholesterolemic rats treated with or without rosiglitazone after exposure to Ang II

\begin{tabular}{lcccc}
\hline & \multicolumn{2}{c}{ Normal rats } & \multicolumn{2}{c}{ Hypercholesterolemic rats } \\
\cline { 2 - 5 } & $\mathrm{NC}$ & $\mathrm{NC}+\mathrm{RGL}$ & $\mathrm{HC}$ & $\mathrm{HC}+\mathrm{RGL}$ \\
\hline Mean & 0.031 & 0.046 & $0.110^{*}$ & $0.0977^{*}$ \\
$\mathrm{SEM}$ & 0.012 & 0.011 & 0.016 & 0.011 \\
\hline${ }^{*} \mathrm{p}<0.01$ & vs. NC and $\mathrm{NC}+\mathrm{RGL} ;{ }^{*} \mathrm{p}<0.01$ & vs. $\mathrm{NC} ;{ }^{\&} \mathrm{p}<0.05$ & vs. NC+RGL \\
\hline
\end{tabular}

Fig. 4. Serum magnesium concentration measured in normal and hypercholesterolemic rats treated with or without rosiglitazone. Hypercholesterolemic rats showed hypomagnesemia and the treatment with RGL did not modify it. Data are expressed as mean \pm SEM. $\diamond \mathrm{p}<0.05$ vs. NC + RGL; ${ }^{*} \mathrm{p}<0.05$ vs. NC and ${ }^{* *} \mathrm{p}<0.01$ vs. NC + RGL evaluated by analysis of variance followed by the Student-Newman-Keuls test. NC, normocholesterolemic rats; NC + RGL, normocholesterolemic rats treated with RGL; HC, hypercholesterolemic rats; $\mathrm{HC}+\mathrm{RGL}$, hypercholesterolemic rats treated with RGL; RGL, rosiglitazone.

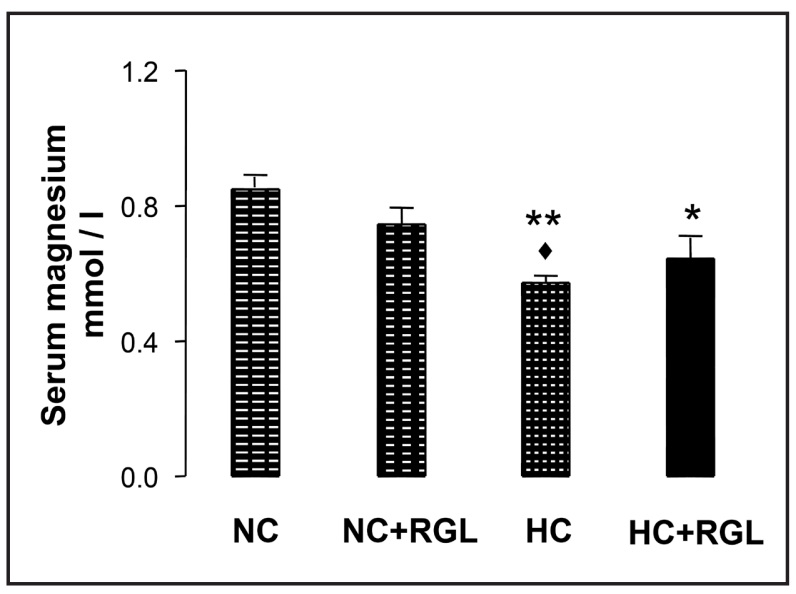

\section{Discussion}

The use of RGL has been restricted in many countries because adverse effects have been reported especially those concerning risks to the cardiovascular system [6-8]. However, there 


\section{Kidney Blood Pressure Research}

is currently little information in literature as to whether the vasodilation effect provoked by the RGL treatment that reduces renal blood flow and GFR may induce ischemic AKI. We did not find evidences to support this hypothesis in normocholesterolemic rats treated with RGL either at baseline or during a vasoconstriction state caused by acute infusion of Ang II. Although NC+RGL showed a reduction in GFR at baseline and during Ang II exposure, the levels of uNGAL were low in these animals, which do not support the diagnosis of AKI. Nevertheless, the treatment with the same selected dose for RGL used in normal rats did not reduce GFR in hypercholesterolemic rats, but increased the levels of uNGAL at baseline and during ANG II infusion. Moreover, we have also found a high score of renal damage in these animals. We did not find changes in the serum levels of TBARS in these animals, but hypomagnesemia was present in both HC and HC + RGL at baseline.

It has been reported that PPAR $\gamma$ agonists relax the vascular smooth muscle cells of the vessels (VSMC) [21-24]. Consequently, PPAR $\gamma$ agonists may reduce vascular resistance by inhibiting L-type $\mathrm{Ca}^{2+}$ channels (VOCC) [23, 24]. In addition, PPAR $\gamma$ agonists also vasodilate both pre- and postglomerular arterioles that decrease the glomerular capillary pressure $\left(\mathrm{P}_{\mathrm{GC}}\right)$ [13] allowing the reduction in glomerular hyperfiltration and albumin excretion when used in diabetic patients [3]. However, the use of PPAR $\gamma$ agonists is not restricted to diabetic patients due to its anti-inflammatory action $[2,9,10]$. Thus, the reduction in $\mathrm{P}_{\mathrm{GC}}$ may diminish GFR and blood supply to tubular epithelial cells predisposing non-diabetic patients using PPAR $\gamma$ agonists to renal ischemia and AKI. Furthermore, the risk to ischemic AKI increases if a vasoconstriction state develops, as for example in patients with low cardiac output due to hypovolemia or heart failure. In this situation, Ang II is released to restore the hemodynamic instability causing a vasoconstriction especially in glomerular arterioles in which VOCC are present [25].

In the present study, we evaluated the renal function in normal rats treated with RGL at a level of $48 \mathrm{mg} / \mathrm{kg}$ of diet for eight days. This dose reduced GFR at baseline without significant changes in diuresis and electrolytes excretion. Song et al [12] reported that normal rats treated with RGL at a level of $96 \mathrm{mg} / \mathrm{kg}$ of diet had reduction in creatinine clearance, but they have also shown reduction in diuresis and sodium excretion. For this reason, we tested the doses of 48 and $24 \mathrm{mg} / \mathrm{kg}$ of diet, and we used the former dose because $24 \mathrm{mg} / \mathrm{kg}$ diet failed to reduce GFR (data not shown).

We observed that a reduction in GFR provoked by RGL treatment in normal rats was not associated with AKI even in the presence of Ang II that elicited diuresis and natriuresis significantly. We verified that uNGAL levels and histologic examination score were at normal range. Our results confirm current information that diuresis and sodium excretion have not been considered as good biomarkers for the diagnosis of AKI [26]. Indeed, uNGAL levels reflect better AKI as shown by Han et al in rats with sepsis [27].

Ang II acts in renal microcirculation operating L-type $\mathrm{Ca}^{2+}$ channels with a clear inhibitory effect managed by nifedipine [25]. Kondo $\mathrm{N}$ et al [28] and Fujimoto $\mathrm{S}$ et al [29] demonstrated in normal rats that azelnidipine attenuated renal injury induced by Ang II exposure because blood flow was improved. The absence of AKI in normal rats treated with RGL may be justified by the possibility that L-type $\mathrm{Ca}^{2+}$ channels were inhibited, which prevented the vasoconstricting action of Ang II. In consequence, blood supply was enough and renal hypoxia did not develop in these animals.

In a recent study, Betz $B$ et al [30] demonstrated beneficial effects in normal rats treated with RGL that were submitted to a protocol of ischemia/reperfusion injury. RGL reversed the downregulation of the mRNA expression of endothelial NO-synthase (eNOS) and inhibited the upregulation of the mRNA of inducible NO-synthase (iNOS). Thus, increases in eNOS may also prevent the deleterious effects exerted by ANG II exposure.

Moreover, we have tested the same protocols in hypercholesterolemic rats because Liu HR et al $[4,5]$ demonstrated benefits in the myocardium of hypercholesterolemic rabbits treated with RGL that were submitted to ischemic insult. We did not choose Zucker rats to perform the experiments as changes in plasma lipid profiles are associated with obesity, glucose intolerance, hypertension and renal sodium retention in these animals [31]. Hence, 


\section{Kidney \\ Blood Pressure Research}

\begin{tabular}{l|l}
\hline Kidney Blood Press Res 2013;38:186-195 \\
\hline DOI: $10.1159 / 000355767$ & (C) 2014 S. Karger AG, Basel
\end{tabular}

Published online: April 08, 2014

www.karger.com/kbr

Dias/Volpini/Helou: Rosiglitazone and AKI

we induced hypercholesterolemia by feeding the rats with a high cholesterol diet for 8 days since the animals become hypercholesterolemic with similar body weight, AP and GFR of their control as we have previously reported $[15,16]$.

Unexpectedly, the same selected dose of RGL that reduced GFR in NC+RGL did not induce any change in GFR of HC+RGL. This finding may indicate impairment in the vasodilating response in $\mathrm{HC}$ rats, which could be due to low serum magnesium concentration found in these animals. It is well known that magnesium depletion causes changes in vascular reactivity preventing the relaxation of vascular smooth muscle cells [32]. In a recent study, we reported the development of hypomagnesemia with high magnesium urinary losses in $\mathrm{HC}$ because the expression of epithelial $\mathrm{Mg}^{2+}$ channels was reduced in the kidney of these animals [16].

Although GFR, urine output and urinary electrolytes excretion in HC+RGL at baseline were similar to HC and NC, the levels of UNGAL were high in HC+RGL at this time. During Ang II exposure, HC animals treated with or without RGL showed high levels of UNGAL predicting the diagnosis of AKI. Moreover, histologic examination showed a high score of renal damage in HC and HC + RGL at the same time that high levels of uNGAL were found. Taken together, we hypothesized that the beneficial effect of RGL in inhibiting L-type $\mathrm{Ca}^{2+}$ channels in VSMC to prevent ischemia induced by the vasoconstricting action of Ang II failed because AKI was already present in $\mathrm{HC}+\mathrm{RGL}$ at baseline.

To investigate if oxidative stress played a role, we assayed TBARS in the serum. Since serum TBARS was similar in all groups, the oxidative stress might not play an important role. TBARS were assayed in two other sets of animals like we performed with uNGAL determinations. We chose to perform this study design, which is illustrated in Fig. 1, to avoid biases due to the long wait to collect samples during Ang II in anesthetized animals. Both uNGAL and TBARS are highly sensitivity methods in which animal deteriorations could lead to misleading interpretations in positive results. In this way, we shortened 60 min of the protocol. Therefore, NC data even in the presence of Ang II did not show increases allowing for the validation as a control group. In any case, we recognize that we cannot totally exclude the role of oxidative stress because we only assayed TBARS and this parameter is less sensitive than others, such as F2-isoprostanes measurements.

Nevertheless, the presence of hypomagnesemia in both HC and HC + RGL may explain the AKI development especially after Ang II exposure, which was also confirmed by histologic examination. As demonstrated by Araujo et al, magnesium supplementation has a protective effect on renal function in the model of ischemia/reperfusion injury [33].

\section{Conclusion}

This study showed evidences to support the hypothesis that RGL acts distinctly in normocholesterolemia and in hypercholesterolemia. In addition, reduction in GFR provoked by RGL did not allow the diagnosis of AKI in normal rats. In contrast, AKI was diagnosed in hypercholesterolemic rats treated with RGL although GFR was within the normal range. Furthermore, hypomagnesemia can be considered a risk factor to AKI in hypercholesterolemic rats especially in those treated with RGL and during exposure to Ang II. Finally, we concluded that RGL may be prescribed with caution in the presence of hypercholesterolemia in spite of its anti-inflammatory beneficial effects. Future experiments must be performed to verify whether other thiazolidinediones may be used without side effects.

\section{Conflict of Interests}

The authors have no conflicts to interest to disclose. 


\section{Kidney \\ Blood Pressure Research}

Dias/Volpini/Helou: Rosiglitazone and AKI

\section{Acknowledgements}

This work was supported by Laboratório de Investigação Médica - HC FMUSP, Fundação Faculdade Medicina and Fundação de Amparo à Pesquisa do Estado de São Paulo (FAPESP). Cristiano Dias was supported by Conselho Nacional de Pesquisa (CNPq). The authors thank Fabiola M. Oshiro-Monreal for her technical assistance help.

\section{References}

1 Yki-Järvinen H: Thiazolidinediones. N Engl J Med 2004;351:1106-1118.

-2 Abdelrahman M, Sivarajah A, Thiemermann C: Beneficial effects of PPAR-gamma ligands in ischemiareperfusion injury, inflammation and shock. Cardiovasc Res 2005;65:772-781.

3 Sarafadis PA, Bakris GL: Protection of the kidney by thiazolidinediones: an assessment from bench to bedside. Kidney Int 2006; 70:1223-1233.

-4 Liu HR, Tao L, Gao E, Qu Y, Lau WB, Lopez BL, Christopher TA, Koch W, Yue TL, Ma XL: Rosiglitazone inhibits hypercholesterolaemia-induced myeloperoxidase upregulation - a novel mechanism for the cardioprotective effects of PPAR agonists. Cardiovasc Res 2009;81:344-352.

-5 Liu HR, Tao L, Gao E, Lopez BL, Christopher TA, Willette RN, Ohlstein EH, Yue TL, Ma XL: Anti-apoptotic effects of rosiglitazone in hypercholesterolemic rabbits subjected to myocardial ischemia and reperfusion. Cardiovasc Res 2004;62:135-144.

6 Nesto R W, Bell D, Bonow RO, Fonseca V, Grundy SM, Horton ES, Le Winter M, Porte D, Semenkovich CF, Smith S, Young LH, Kahn R: Thiazolidinedione use, fluid retention, and congestive heart failure: a consensus statement from the American Heart Association and American Diabetes Association. Circulation 2003;108:2941-2948.

7 Home PD, Pocock SJ, Beck-Nielsen H, Gomis R, Hanefeld M, Jones NP, Komajda M, McCurray JJ: Rosiglitazone evaluated for cardiovascular outcomes - an interim analysis. N Engl J Med 2007;357:28-38.

8 Nissen SE, Wolski K: Rosiglitazone Revisited. An updated meta-analysis of risk for myocardial infarction and cardiovascular mortality. Arch Intern Med 2010;170:1191-1201.

99 Yang J, Zhou Y, Guan Y: PPAR $\gamma$ as a therapeutic target in diabetic nephropathy and other renal diseases. Curr Opin Nephrol Hypertens 2012;21:97-105.

10 Zhu M, Flynt L, Ghosh S, Mellema M, Banerjee A, Williams E, Panettrieri Jr RA, Shore SA: Anti-inflammatory effects of thiazolidinediones in human airway smooth muscle cells. Am J Respir Cell Mol Biol 2011;45:111119.

11 Guan YF, Hao C, Cha DR, Rao R, Lu W, Kohan DE, Magnuson MA, Redha R, Zhang Y, Breyer MD: Thiazolidinediones expand body fluid volume through PPAR $\gamma$ stimulation of ENaC-mediated renal salt absorption. Nat Med 2005;11:861-866.

12 Song J, Knepper MA, Hu X, Verbalis JG, Ecelbarger CA: Rosiglitazone activates renal sodium- and waterreabsorptive pathways and lowers blood pressure in normal rats. J Pharmacol Exp Ther 2004;308:426433.

13 Arima S, Kohagura K, Takeuchi K, Taniyama Y, Sugawara A, Ikeda Y, Abe M,Omata K, Ito S: Biphasic vasodilator action of troglitazone on the renal microcirculation. J Am Soc Nephrol 2002;13:342-349.

14 National Research Council: Guide for the Care and Use of Laboratory Animals. Eight Edition. Washington (DC): The National Academies Press, 2011.

15 Tamaoki L, Oshiro-Monreal FM, Helou CMB: Effects of nicotine exposure on renal function of normal and hypercholesterolemic rats. Am J Nephrol 2009;30:377-382.

-16 Favaro VF, Oshiro-Monreal FM, Bragança AC, Andrade LC, Seguro AC, Helou CMB: High cholesterol feeding may induce tubular dysfunction resulting in hypomagnesemia. Kidney Blood Press Res 2012;35:137-146.

17 Zhang XZ, Qiu C, Baylis C: Sensitivity of the segmental renal arterioles to angiotensin II in the aging rat. Mech Ageing Dev 1997;97:183-192. 


\section{Kidney \\ Blood Pressure Research}

\begin{tabular}{l|l}
\hline Kidney Blood Press Res 2013;38:186-195 \\
\hline DOI: 10.1159/000355767 & $\begin{array}{l}\text { C) 2014 S. Karger AG, Basel } \\
\text { www.karger.com/kbr }\end{array}$ \\
\hline Published online: April 08, 2014 &
\end{tabular}

18 Führ J, Kaczmarczyk J, Krüttgen CD: Eine einfache colorimetrische Methode zur Inulinbestimmung für Nieren-Clearance - Untersuchungen bei Stoffwechselgesunden und Diabetikern. Klin Wochenschr 1955;33:729-730.

19 Miyaji T, Kato A, Yasuda H, Fujigaki Y, Hishida A: Role of the increase in p21 in cisplatin-induced acute renal failure in rats. J Am Soc Nephrol 2001;12:900-908.

20 Shimizu MHM, Danilovic A, Andrade L, Volpini RA, Libório AB, Sanches TRC, Seguro AC: N-cetylcysteine protects against renal injury following bilateral ureteral obstruction. Nephrol Dial Transplant 2008;23:3067-3073.

-21 Liu Y, Tian XY, Mao G, Fang X, Fung ML, Shyy JYJ, Huang Y, Wang N: Peroxisome proliferator-activated receptor- $\gamma$ ameliorates pulmonary arterial hypertension by inhibiting 5-hydroxytryptamine $2 \mathrm{~B}$ receptor. Hypertension 2012;60:1471-1478.

22 Buchanan TA, Meehan WP, Jeng YY, Yang D, Chan TM, Nadler JL, Scott S, Rude RK, Hsueh WA: Blood pressure lowering by pioglitazone. Evidence for a direct vascular effect. J Clin Invest 1995;96:354-360.

23 Zhang F, Sowers JR, Ram JL, Standley PR, Peuler JD: Effects of pioglitazone on calcium channels in vascular smooth muscle. Hypertension 1994;24:170-175.

-24 Song J, Walsh MF, Igwe R, Ram JL, Barazi M, Dominguez LJ, Sowers JR: Troglitazone reduces contraction by inhibition of vascular smooth muscle cell $\mathrm{Ca}^{2+}$ currents and not endothelial nitric oxide production. Diabetes 1997;46:659-664.

-25 Helou CMB, Marchetti J: Morphological heterogeneity of renal glomerular arterioles and distinct [Ca $\left.{ }^{2+}\right] \mathrm{i}$ responses to Ang II. Am J Physiol 1997;273:F84-F96.

26 Perazella MA, Coca SG: Traditional urinary biomarkers in the assessment of hospital-acquired AKI. Clin J Am Soc Nephrol 2012;7:167-74.

27 Han M, Li Y, Liu M, Li Y, Cong B: Renal neutrophil gelatinase associated lipocalin expression in lipopolysaccharide-induced acute kidney injury in the rat. BMC Nephrology 2012;13:25-35.

28 Kondo N, Kiyomoto H, Yamamoto T, Miyatake A, Sun GP, Rahman M, Hitomi H, Moriwaki K, Hara T, Kimura S, Abe Y, Kohno M, Nishiyama A: Effects of calcium channel blockade on angiotensin II-induced peritubular ischemia in rats. J Pharmacol Exp Ther 2006;316:1047-1052.

29 Fujimoto S, Satoh M, Nagasu H, Horike H, Sasaki T, Kashihara N: Azelnidipine exerts renoprotective effects by improvement of renal microcirculation in angiotensin II infusion rats. Nephrol Dial Transplant 2009;24:3651-3658.

-30 Betz B, Schneider R, Kress T, Schick MA, Wanner C, Sauvant C: Rosiglitazone affects nitric oxide synthase and improves renal outcome in a rat model of severe ischemia/reperfusion injury. PPAR Research 2012;2012:219319.

31 Kurtz TW, Morris RC, Pershadsingh HA: The Zucker fatty rat as a genetic model of obesity and hypertension. Hypertension 1989;13:896-901.

32 Resnick LM, Bardicef O, Altura BT, Alderman MH, Altura BM: Serum ionized magnesium: relation to blood pressure and racial factors. Am J Hypertens 1997;10:1420-1424.

-33 Araujo M, Andrade L, Coimbra TM, Rodrigues Jr AC, Seguro AC: Magnesium supplementation combined with N-Acetylcysteine protects against postischemic acute renal failure. J Am Soc Nephrol 2005;16:33393349. 